\title{
Treatment response in child anxiety is differentially related to the form of maternal anxiety disorder
}

Article

Published Version

Cooper, P. J., Gallop, C., Willetts, L. and Creswell, C. (2008) Treatment response in child anxiety is differentially related to the form of maternal anxiety disorder. Behavioural and Cognitive Psychotherapy, 36 (1). pp. 41-48. ISSN 1352-4658 doi: https://doi.org/10.1017/s1352465807003943 Available at https://centaur.reading.ac.uk/14108/

It is advisable to refer to the publisher's version if you intend to cite from the work. See Guidance on citing.

To link to this article DOI: http://dx.doi.org/10.1017/s1352465807003943

Publisher: Cambridge University Press

All outputs in CentAUR are protected by Intellectual Property Rights law, including copyright law. Copyright and IPR is retained by the creators or other copyright holders. Terms and conditions for use of this material are defined in the End User Agreement.

www.reading.ac.uk/centaur 
Central Archive at the University of Reading

Reading's research outputs online 


\title{
Treatment Response in Child Anxiety is Differentially Related to the Form of Maternal Anxiety Disorder
}

\author{
Peter J. Cooper, Catherine Gallop, Lucy Willetts and Cathy Creswell
}

University of Reading, $U K$

\begin{abstract}
An examination was made of the extent to which maternal anxiety predicted response to treatment of children presenting with an anxiety disorder. In a sample of 55 children referred to a local NHS CAMH service for treatment of an anxiety disorder, systematic mental state interview assessment was made of both mothers and children, and both completed self-report questionnaires to assess aspects of anxiety, both immediately before the children received treatment and following treatment. Children of mothers with anxiety disorder overall responded less well to treatment than children of mothers with no anxiety disorder. There was some diagnostic specificity in this in that children of mothers with GAD did as well in treatment as children whose mothers had no anxiety, whereas children of mothers with social phobia did poorly. The outcome for children with anxiety appears to be related to the presence and nature of maternal anxiety. It would seem prudent that treatment of children with anxiety involves assessment of maternal anxiety. It is important to establish in systematic investigation whether treatment of maternal anxiety improves the outcome for child anxiety.
\end{abstract}

Keywords: Child anxiety, maternal anxiety, child outcome, treatment outcome.

\section{Introduction}

The outcome for children treated for anxiety disorders is highly variable. James, Soler and Wetherall (2006), in a recent Cochrane review of trials for child anxiety disorders, concluded that around half of children with anxiety disorder who were treated with CBT remit, but the range in remission rates reported is substantial (Cartwright-Hatton, Roberts, Chitsabean, Fothergill and Harrington, 2004; Compton et al., 2004). The factors responsible for this variability are uncertain; there has been little research into predictive factors and the findings are inconsistent (Southam-Gerrow, Kendall and Weersing, 2001). This inconsistency appears to be a function of differences in treatments delivered and variation in assessments procedures, as well as variability in patient populations. One prognostic factor, amongst others, likely to be important is maternal emotional disturbance (Crawford and Manassis, 2001; Southam-Gerow et al., 2001). Anxiety disorder amongst the mothers of anxious children is significantly raised above the base rate (Last, Hersen, Kazdin, Francis and Grubb, 1987; Last, Hersen, Kazdin, Orvaschel and Perrin, 1991); indeed, a recent bottom up family history study found that twothirds of the mothers of children presenting for treatment of an anxiety disorder themselves had

Reprint requests to Peter J. Cooper, Winnicott Research Unit, School of Psychology and Clinical Language Sciences, University of Reading, 3 Early Gate, Reading RG6 6AL, UK. E-mail: p.j.cooper@reading.ac.uk 
a current anxiety disorder, and that there was no raised rate of current disorder amongst fathers (Cooper, Fearn, Willetts, Seabrook and Parkinson, 2006). Indeed, there are suggestions within the literature that providing treatment for maternal anxiety may well improve the outcome of child anxiety (Windheuser, 1977; Cobham, Dadds and Spence, 1998), although this remains to be demonstrated in systematic research.

There seem to be two ways in which maternal anxiety could interfere with child response to treatment. First, there is evidence to suggest that maternal anxiety is associated with patterns of parenting that are themselves anxio-genic (Wood, McLeod, Sigman, Hwang and Chu, 2003); so an anxious mother's over-controlling parenting style, for example, could militate against a treatment aimed at promoting her child's autonomy. Second, treatments commonly require the mother to provide support and encouragement of child exposure to feared stimuli (e.g. Dadds and Barrett, 2001) and the mother's own anxiety may interfere with this requirement. For example, a mother with social phobia may well experience difficulties in encouraging her socially anxious child to engage in more social activities.

The clinical implications of maternal anxiety predicting child treatment response are considerable. Indeed, were this to be confirmed, it would suggest a wholly novel management strategy for child anxiety disorder that presents in the context of maternal anxiety. Before proposing such radical change to clinical practice it is important that the association between maternal anxiety and child outcome be confirmed. In this preliminary investigation, the outcome of a group of children treated in a routine child and adolescent mental health (CAMH) service for an anxiety disorder was therefore examined in relation to the level and nature of maternal anxiety disorder.

\section{Method}

A sample for the current study was derived from a consecutive series of 67 children referred to a CAMH service with a primary clinical diagnosis of an anxiety disorder. Their mental state was systematically assessed using the ADIS-C/P (Silverman and Albano, 1996) with diagnoses based on information from both the mother and the child. The children also completed three questionnaires: State-Trait Anxiety Inventory-A Trait (Spielberger, 1973), the Social Anxiety Scale for Children - child version (LaGreca, Kraslow Dandes, Wick, Shaw and Stone, 1988), and the Penn State Worry Questionnaire for children (Chorpita, Tracey, Brown, Collica and Barlow, 1997). In addition, the mental state of the mothers of these children was independently assessed using the SCID (First, Spitzer, Gibbon and Williams, 1995). Mothers also completed the State-Trait Anxiety Inventory-A Trait (Spielberger, Gorsuch and Lushene, 1983), the Social Phobia Scale and the Social Interaction Anxiety Scale (Mattick and Clarke, 1998), and the Penn State Worry Questionnaire (Meyer, Miller, Metzger and Borkovec, 1990).

An assessment of the reliability of the mental state assessments of the mothers was made by a second assessor making diagnoses based on $15 \%$ of the taped SCID interviews. Kappas were 1.00 for all current diagnoses (apart from dysthymia and agoraphobia without panic, which were incalculable because there were no instances), and ranged from 0.82 to 1.00 for past disorders. A similar assessment was made for the child diagnoses, and reliability was found to be equally good (i.e. Kappas from 0.84 to 1.00 ).

The children were managed within the general CAMH service. Half $(n=34)$ were provided with individual or group CBT, while the others received a range of treatments, principally parental advice or psychiatric review. There was no relation between the form of treatment 
Table 1. Questionnaire scores of mothers and children before and after child treatment

\begin{tabular}{|c|c|c|c|c|}
\hline & \multicolumn{2}{|c|}{ Mothers with anxiety disorder $N=29$} & \multicolumn{2}{|c|}{ Mothers with no anxiety disorder $N=26$} \\
\hline & Pre-treatment & Post-treatment & Pre-treatment & Post-treatment \\
\hline \multicolumn{5}{|c|}{ Mother self-report } \\
\hline STAI-Trait & $46.79(10$ & 44.30( & $40.04(9$ & $39.00(10$ \\
\hline PSWQ & $48.76(1$ & 47.30( & $40.35(11.87,24-72)$ & $41.54(14.35,24-80)$ \\
\hline Mattick SPS & $19.45(16.03,0-55)$ & $12.41(9.57,0-33)$ & $9.08(8.98,0-30)$ & $7.96(8.80,0-35)$ \\
\hline \multicolumn{5}{|c|}{ Child self-report } \\
\hline STAIC-Trait & $40.12(6.56,30-5$ & $37.10(7.7$ & $36.92(8$. & $32.81(7.85,23-52)$ \\
\hline PSWQ-C & $22.62(9.98,7-42)$ & $19.00(9.86,4-40)$ & $21.08(10.95,2-41)$ & $17.35(9.67,3-37)$ \\
\hline SCAS-C & $47.62(12.38,27-83)$ & $47.52(12.29,23-68)$ & $42.24(14.86,23-86)$ & $37.15(13.76,11-66)$ \\
\hline
\end{tabular}

delivered and the level or nature of anxiety in either the children or the mothers. Efforts were made to reassess these children using the same measures of child anxiety (ADIS- C/P, STAIC, SASC-c; PSWQ-c). Assessments were completed on 55 of the patients. The remainder were either not contactable or were unwilling to comply with reassessment. The report below concerns these 55 children and their mothers.

\section{Results}

\section{The mothers}

Twenty-nine of the 55 mothers (55\%) were found at the initial assessment to have a current anxiety disorder and $42(76 \%)$ had a life-time anxiety disorder. Most had a single current anxiety disorder, the most common being specific phobia (44\%), social phobia $(25.5 \%)$ and GAD (20\%). Life-time rates for these disorders were $47 \%, 40 \%$, and $31 \%$ respectively. A few mothers were receiving either counselling or medication, but since this was not related to child outcome, it was not considered further. As shown in Table 1 there was no significant change over the two assessment points in levels of anxiety on any of the measures for either the mothers with an anxiety disorder or the mothers free from anxiety disorder, except on one dimension: social anxiety (SPS) fell significantly for mothers with an anxiety disorder $(t(25)=2.07, p=.05)$.

\section{The children}

The children ranged from 6 to 15 years old; $54.5 \%$ were girls. All of them presented with two or more anxiety disorders. The most common of these were GAD (67\%), social phobia (49\%), separation anxiety disorder (47\%), and specific phobia (47\%). The mean anxiety scores before treatment for those whose mothers had an anxiety disorder did not differ from the scores of those whose mothers were free from anxiety disorder on any of the questionnaire measures (see Table 1). 


\section{Prediction of child outcome}

Preliminary analysis revealed that length of time since initiation of treatment, method of treatment, presence of other axis I disorders in the child, and child age and gender were all unrelated to either child's diagnostic status at follow-up or their scores on the follow-up questionnaires (although those who received CBT did somewhat better). These factors were therefore ignored in subsequent analyses.

\section{Association between (non-specific) maternal anxiety disorder and child treatment outcome}

Fourteen $(25.5 \%)$ of the children were free from a DSM-IV anxiety disorder following treatment; and although more than twice as many children whose mother did not have an anxiety disorder were themselves free of anxiety following treatment than were children whose mothers did have an anxiety disorder, this was not a significant difference (33\% and $15 \%$ respectively; $\chi^{2}=2.20, d f=1, p=.14$ ). As can be seen from Table 1 , the children of the mothers who were free from an anxiety disorder experienced a significant reduction following treatment on all three continuous measures of anxiety (Trait $t(24)=2.75, p=.01$; PSWQ $t(25)=2.29, p=.03$; SASC $t(24)=2.25, p=.03)$. In contrast, the children whose mothers had an anxiety disorder did not evidence a reliable reduction in level of trait anxiety $(t(24)=1.98, p=.06)$, worry $(t(25)=1.57, p=.13)$, or social anxiety $(t(25)=.25, p=.80)$.

\section{Association between specific maternal anxiety disorder and child treatment outcome}

To explore further the relation between child outcome and specific maternal anxiety disorders, analyses of variance were conducted to examine the association between the presence of maternal diagnoses of Social Phobia or GAD (the most common maternal disorders, apart from Specific Phobia) and related child questionnaire measures (SAS-C and PSWQ-C) at follow-up, covarying the child's response on that same questionnaire measure at the intake assessment. Analyses were also conducted in relation to presence of a maternal diagnosis of major depressive disorder (present in 9.1\%). Scores on the PSWQ-C at the follow-up assessment tended to be associated with a maternal diagnosis of $\operatorname{GAD}(F(1)=3.29, p=.08)$, but not Social Phobia $(F(1)=.52, p=.48)$ or Depression $(F(1)=.85, p=.36)$, with children of mothers with GAD showing particular improvement on the PSWQ-C. Indeed, the degree of improvement on the PSWQ-C did not differ for the children of mothers with GAD and the children of non-anxious mothers $(F(1)=1.85, p=.18)$. In contrast, there was a trend towards the presence of a history of maternal Social Phobia to be associated with higher scores on the SASC at the follow-up assessment $(F(1)=3.72, p=.06)$ but not $\operatorname{GAD}(F(1)=.20, p=.66)$ or Depression $(F(1)=.19, p=0.66)$.

Correlations were also run, for the group as a whole, between the level of maternal anxiety and the level of child anxiety at follow-up. This was done for the corresponding measures (e.g. maternal PSWQ with child PSWQ), partialling out the child's pre-treatment score. Whilst neither the level of general (trait) anxiety or worry (PSWQ) in the mother were predictive of the level of general (trait) anxiety $(r(46)=0.07, p=.63$ ) and worry (PSWQ: $r(48)=-.03$, $p=.82)$ in the child, the child's level of social anxiety following treatment was significantly predicted by the mothers' pre-treatment score on both the SPS $(r(47)=.36, p=.01)$ and the PSWQ $(r(47)=0.30, p=.03)$. The latter association ceased to be significant when account 
Table 2. Questionnaire scores before and after treatment of children of mothers with social phobia, GAD, and depressive disorder

\begin{tabular}{|c|c|c|c|c|c|c|}
\hline & \multicolumn{2}{|c|}{ Maternal social phobia } & \multicolumn{2}{|c|}{ Maternal GAD } & \multicolumn{2}{|c|}{ Maternal major depressive disorder } \\
\hline & Present $n=14$ & Absent $n=41$ & Present $n=11$ & Absent $n=44$ & Present $n=5$ & Absent $n=50$ \\
\hline \multicolumn{7}{|l|}{ SAS-C } \\
\hline Pre-treatment & $50.25(13.82,6.83)$ & $43.36(13.52,23.86)$ & $51.09(16.68,27-83)$ & $43.30(12.60,23-86)$ & $56.40(15.73,44-83)$ & $43.74(13.15,23-86)$ \\
\hline Post-treatment & $51.21(12.28,26-68)$ & $39.68(13.31,11-66)$ & $47.18(12.62,26-66)$ & $41.48(14.10,11-68)$ & $56.40(15.73,44-83)$ & $42.00(14.19,11-68)$ \\
\hline \multicolumn{7}{|l|}{ PSWQ-C } \\
\hline Pre-treatment & $22.00(9.07,7-33)$ & $21.80(10.88,2-42)$ & $24.73(10.41,9-42)$ & $21.07(10.39,2-41)$ & $27.20(6.54,5-18)$ & $21.46(10.67,2-42)$ \\
\hline Post-treatment & $20.43(8.06,7-35)$ & $17.46(10.20,3-40)$ & $15.36(8.65,4-32)$ & $18.93(9.93,3-40)$ & $23.80(11.69,13-40)$ & $17.66(9.46,3-38)$ \\
\hline
\end{tabular}


was taken of maternal SPS scores $(r(46)=.20, p=.17)$; on the other hand, when PSWQ scores were controlled for, the association between change in child SASC and maternal SPS remained significant $(r(46)=.29, p=.05)$. The association between maternal worry scores and child anxiety score post-treatment, therefore, appears to be due to the overlap with measures of maternal social anxiety.

\section{Discussion}

The implications for the outcome of children with anxiety disorders of the high rate of maternal anxiety has not received adequate attention in the research literature. The current preliminary study addressed this question by making systematic assessment of maternal anxiety and relating this to the child's response to treatment, in a sample of anxious children referred to a local CAMH service. The notable finding to emerge from the current study was that child response to treatment for anxiety was related to both the presence and nature of maternal anxiety. Thus, children whose mothers were anxious did less well in treatment as a group than children whose mothers were free of anxiety; however, in contrast to children whose mothers had GAD, who did as well in treatment as children whose mothers were free from anxiety, children of mothers with social phobia responded particularly poorly.

The current study must be regarded as preliminary as it had several limitations, and only tentative conclusions can be drawn from it. This was a small clinic sample of anxious children who received a variety of interventions in a non-specialist NHS setting; and the clinical improvement in these children was far less favourable than obtained in the CBT trials. It is possible that where better clinical results are obtained, the association between maternal disorder and child outcome found in the current sample might well be attenuated. It is important that the critical analyses be repeated on a larger sample of children where a standard treatment is delivered and a better clinical response obtained.

It is worth noting that the important finding emerged from the current study because a systematic diagnostic assessment was made of the mothers; had a general measure of maternal anxiety been used, with no regard to the specific form of the anxiety, the impact of maternal anxiety on child outcome would have been much less clear. This may account for the fact that several other studies that have not taken account of diagnostic specificity have not found an association between maternal anxiety and child treatment outcome (e.g. Rapee, 2000).

Assuming that the findings of the current study are robust, there are at least three important questions that arise. First, what is it about social phobia that militates against treatment effectiveness? One possible answer, as suggested earlier, is that maternal social phobia specifically interferes with the therapeutic strategies proposed in treatment. For example, those with social phobia, however well motivated, are likely to find that their own anxiety disorder impairs their ability to assist their child in the therapeutic process, either due to difficulties in engaging in treatment or due to an association between maternal social anxiety and "anxio-genic" parenting behaviours. Potential parenting behaviours that are commonly associated with child anxiety include modelling of fearful responses and an over-involved style (e.g. Wood et al., 2003). Indeed maternal social phobia has been found to be associated with increased fear expression and a lack of encouragement to the child in novel social situations (Murray, Cooper, Creswell, Schofield and Sack, 2007). Whether maternal social phobia is specifically related to maternal over-involvement has not to date been established but clearly 
warrants further research, as does the association between these parenting behaviours and child treatment outcome.

The second question is whether other maternal anxiety disorders have a similar adverse impact on child response to treatment. For example, maternal agoraphobia and, possibly, panic disorder might interfere with a mother's ability to assist her child in treatment in much the same way as we have suggested that social phobia does. The third question concerns the extent to which child response to treatment is improved by treating the maternal anxiety disorder. If the association is genetically based, treating maternal anxiety could be expected to have no impact on child outcome. If, however, the process by which maternal anxiety impedes child therapeutic progress is as we have suggested above, treatment of the maternal anxiety could provide the means to making the mother a more effective ally in the therapeutic process and thereby improve child response to treatment. All of these questions are in need of empirical examination.

\section{References}

Chorpita, B. F., Tracey, S. A., Brown, T. A., Collica, T. J. and Barlow, D. H. (1997). Assessment of worry in children and adolescents: an adaptation of the Penn State Worry Questionnaire. Behaviour Research and Therapy, 35, 569-581.

Cartwright-Hatton, S., Roberts, C., Chitsabean, P., Fothergill, C. and Harrington, R. (2004). Systematic review of the efficacy of cognitive-behaviour therapies for childhood and adolescent anxiety disorders. British Journal of Clinical Psychology, 43, 421-436.

Cobham, V. E., Dadds, M. R. and Spence, S. H. (1998). The role of parental anxiety in the treatment of childhood anxiety. Journal of Consulting and Clinical Psychology, 66, 893-905.

Compton, S. N., March, J. S., Brent, D., Albano, A. M., Weering, R. and Curry, J. (2004). Cognitive-behavioral psychotherapy for anxiety and depressive disorders in children and adolescents: an evidence-based medicine review. Journal of the American Academy of Child and Adolescent Psychiatry, 43, 930-959.

Cooper, P. J., Fearn, V., Willetts, L., Seabrook, H. and Parkinson, M. (2006). Affective disorder in the parents of a clinic sample of children with anxiety disorders. Journal of Affective Disorders, 93, 205-212.

Crawford, M. A. and Manassis, K. (2001). Familial predictors of treatment outcome in child anxiety disorders. Journal of the American Academy of Child and Adolescent Psychiatry, 40, 1182-1189.

Dadds, M. R. and Barrett, P. M. (2001). Practitioner Review: Psychological management of anxiety disorders in childhood. Journal of Child Psychology and Psychiatry, 42, 999-1011.

First, M. B., Spitzer, R. L., Gibbon, M. and Williams, J. B. W. (1996). Structured Clinical Interview for DSM-IV Axis I Disorders: research version. Washington: American Psychiatric Press.

James, A., Soler, A. and Wetherall, R. (2006). Cognitive behavioural therapy for anxiety disorders in children and adolescents (Review). The Cochrane Library, 1, 1-25.

LaGreca, A. M., Dandes, S. K., Wick, P., Shaw, K. and Stone, W. L. (1988). Development of the Social Anxiety Scale for Children: reliability and concurrent validity. Journal of Clinical Child Psychology, $17,84-91$.

Last, C. G., Hersen, M., Kazdin, A. E., Francis, G. and Grubb, H. J. (1987). Psychiatric illness in the mothers of anxious children. American Journal of Psychiatry, 144, 1580-1583.

Last, C. G., Hersen, M., Kazdin, A., Orvaschel, H. and Perrin, S. (1991). Anxiety disorders in children and their families. Archives of General Psychiatry, 48, 928-934.

Mattick, R. P. and Clark, J. C. (1998). Development and validation of measures of social phobia scrutiny fear and social interaction anxiety. Behaviour Research and Therapy, 36, 455-470. 
Meyer, T. J., Miller, M. L., Metzger, R. L. and Borkovec, T. D. (1990). Development and validation of the Penn State Worry Questionnaire. Behaviour Research and Therapy, 28, 487-495.

Murray, L., Cooper, P. J., Creswell, C., Schofield, E. and Sack, C. (2007). The effects of maternal social phobia on mother-infant interactions and infant social responsiveness. Journal of Child Psychology and Psychiatry, 48, 45-52.

Rapee, R. M. (2000). Group treatment of children with anxiety disorders: outcome and predictors of treatment response. Australian Journal of Psychology, 52, 125-129.

Silverman, W. K. and Albano, A. M. (1996) The Anxiety Disorders Interview Schedule for DSM-IV: child and parent versions. San Antonio, TX: Psychological Corporation.

Spielberger, C. D. (1973). State-Trait Anxiety Inventory for Children ("how I feel questionnaire"). Palo Alto, Ca: Consulting Psychologists Press Inc.

Spielberger, C. D., Gorsuch, R. L. and Lushene, R. E. (1983). State-Trait Anxiety Inventory. Palo Alto, Ca: Consulting Psychologists Press Inc.

Southam-Gerow, M. A., Kendall, P. C. and Weersing, V. R. (2001) Examining outcome variability: correlates of treatment response in a child and adolescent anxiety clinic. Journal of Clinical Child Psychology, 30, 422-436.

Windheuser, H. J. (1977). Anxious mothers as models for coping with anxiety. Behavioural Analysis and Modification, 2, 39-58.

Wood, J. J., McLeod, B. D., Sigman, M., Hwang, W. and Chu, B. C. (2003). Parenting and childhood anxiety: theory, empirical findings, and future directions. Journal of Child Psychology and Psychiatry, $44,134-151$. 